\title{
Influence of composite fibers on the properties of heavy concrete
}

\author{
Marsel Nurtdinov ${ }^{1 *}$, Vadim Solovyev ${ }^{1}$, Alexander Panchenko ${ }^{1}$ \\ ${ }^{1}$ Moscow State University of Civil Engineering, Department of Technologies of Binding Materials \\ and Concretes, 129337 Moscow, Russia
}

\begin{abstract}
The article presents the results of research an effect of glassplastic fiber on the properties of heavy concrete. It determined that adding glass-plastic fibers in heavy concrete compositions in an amount of 0.5 to $2.5 \%$ by volume leads to decreasing of slump from 20 to $5 \mathrm{~cm}$, increasing air entrainment on $0.3 \ldots 0.6 \%$ and reduction in density to about $50 \mathrm{~kg} / \mathrm{m} 3$. Found dependence of the strength properties of concrete classes B20, B30 and B40 depending on the content of glass-plastic fibers. Introduction of fibers into concretes of different classes in an amount up to $2.0 \%$ by volume leads to an increase in the compressive strength on $7 \ldots 10 \%$, tensile strength at bending - up to $14 . . .36 \%$. Defined the perspectives of the use of glass-plastic fiber and ways to improve efficiency in the heavy concrete.
\end{abstract}

\section{Introduction}

In present fiber concrete technology as high modulus disperse-reinforcing components, that increase strength and deformation properties of concrete, used steel fiber of different geometric dimensions, as well as glass and basalt fiber. Each of the used reinforcing components has its own drawbacks - steel fiber besides a considerable mass and a propensity to balling also modifies thermal properties of concrete [1], glass and basalt fibers are breaking at mixing and partially dissolved by reacting with the concrete matrix. In this regard, developing in recent years various types of composite fiber - glass and carbon fiber, causing considerable interest and requiring detailed study [2-4].

Glass-plastic composite fiber (Figure 1) is produced by pultrusion - pulling glass thread through a die heated to a certain temperature at which the polymerization process of the matrix occurs. Fiber length is $40 \mathrm{~mm}$, the diameter is $0.7 \ldots 0.9 \mathrm{~mm}$, the geometric factor $45 \ldots 60$, density $1.54 \mathrm{~g} / \mathrm{cm} 3$, a modulus of elasticity is about $50 \mathrm{GPa}$ (determined on the samples of armature of $4 \mathrm{~mm}$ diameter, made from the same materials and with the same technology).

\footnotetext{
${ }^{1}$ Corresponding author: nurtdinovmarsel@gmail.com
} 


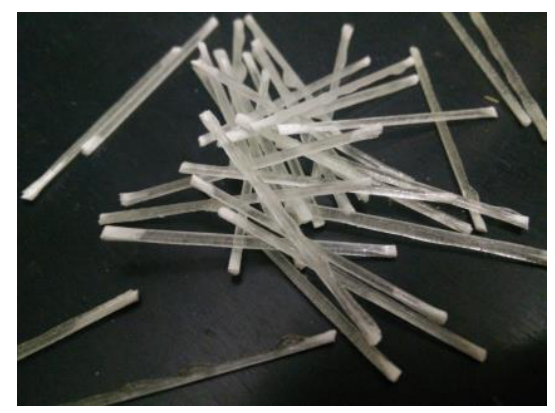

Fig. 1. Glass-plastic fiber.

\section{Experimental part}

To estimate the effect of the glass-plastic fiber on properties of concrete mixtures were used three control compositions of concrete classes B20, B30 and B40, with the same slump of $20 \mathrm{~cm}$, shown in Table 1.

Table 1. Test compositions of heavy concretes.

\begin{tabular}{|c|c|c|c|}
\hline \multirow{2}{*}{ Materials, kg per $\mathbf{1} \mathbf{~ m}^{\mathbf{3}}$. } & \multicolumn{3}{|c|}{ Concrete class } \\
\cline { 2 - 4 } & $\mathbf{B 2 0}$ & $\mathbf{B 3 0}$ & $\mathbf{B 4 0}$ \\
\hline Water, GOST 23732-2011 & 210 & 210 & 200 \\
\hline $\begin{array}{c}\text { Cement LEM II/ A-K 42,5 H, GOST } \\
\text { 31108-2003 }\end{array}$ & 290 & 370 & 450 \\
\hline $\begin{array}{c}\text { Granite rubble, fraction 5-20 mm } \\
\text { GOST 8269.0-97 }\end{array}$ & 1060 & 1060 & 1060 \\
\hline $\begin{array}{c}\text { Sand, fineness modulus 2,1 by GOST } \\
\text { 8736-2014 }\end{array}$ & 760 & 710 & 660 \\
\hline Plasticizer Sika T-34 & 4.35 & 5.18 & 6.32 \\
\hline
\end{tabular}

Influence of glass-plastic fibers on the properties of concrete mixtures was evaluated by slump, air entrainment and the density of concrete mixtures, determined according to GOST 10181. The test results are shown in Figures 2, 3 and 4 . The fiber content at mixtures $\left(\mu_{\mathrm{v}}\right)$ ranged from 0.5 to $2.5 \%$ by volume.

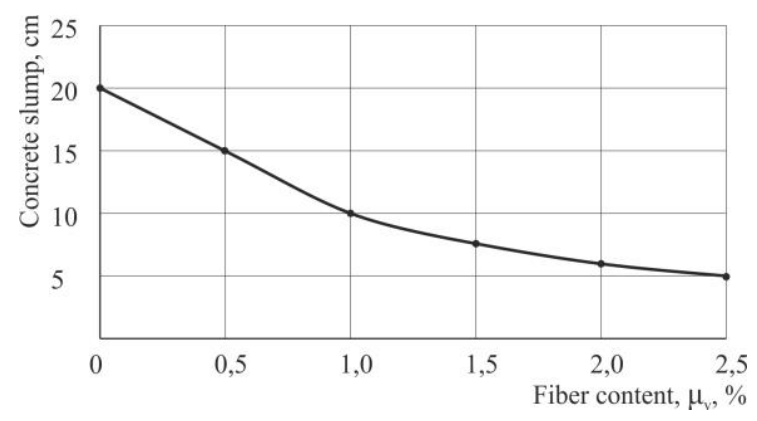

Fig. 2. Concrete slump depending on fiber percentage. 


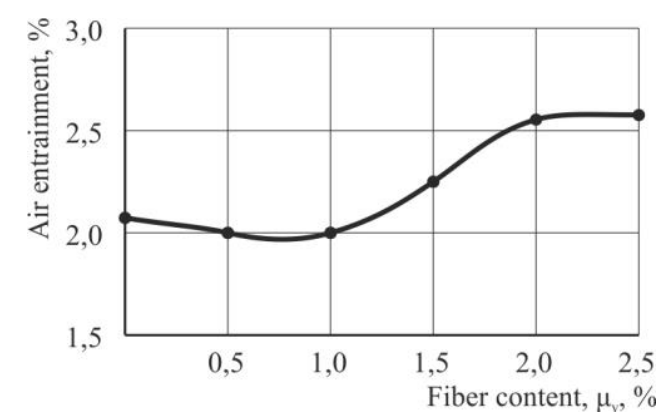

Fig. 3. Air entrainment depending on fiber percentage.

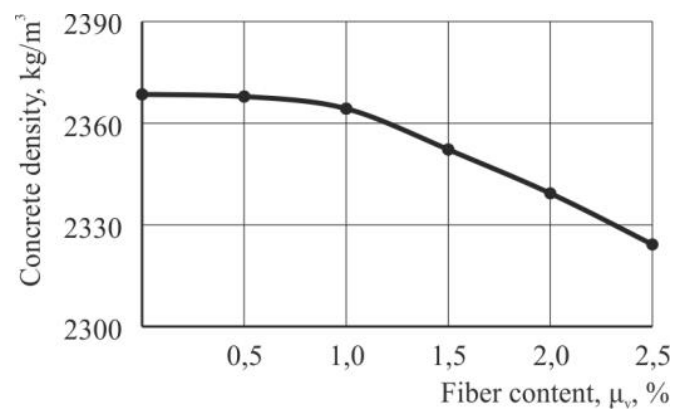

Fig. 4. Density depending on fiber percentage.

When glass-plastic fibers entered to $2.5 \%$ by volume (maximum content of the fibers in the mixture, determined experimentally) workability is reduced from 20 to $5 \mathrm{~cm}$, and the obtained dependence almost linear, does not depend on the composition of the concrete mix.

Air entrainment of different mixtures with fiber content up to $1.5 \%$ varies insignificantly, due to its smooth surface formed by epoxy resin on which there is no air entrapment during mixing. After content of fiber more than $1.5 \%$ air entrainment increases by $0.3 \ldots 0.6 \%$ by reducing the fluidity of the concrete mix.

The density of the concrete mix after adding fibers in an amount up to $2.5 \%$ is reduced on $50 \mathrm{~kg} / \mathrm{m} 3$, due to the increase in volume fiber content with lower density than the other components and improve of air entrainment.

It should be noted the identical type of dependencies, slump, air entrainment, and the density of concrete mixtures of various compositions with the content of glass-plastic fibers. That will allow to use this dependencies in correcting the compositions of fiberreinforced concretes, independently from composition of the concrete matrix.

Effect of glass-plastic fibers on the strength characteristics of concretes performance estimated by the compressive strength test and tensile strength at bending test with specimens sizes $100 \times 100 \times 100$ and $100 \times 100 \times 400 \mathrm{~mm}$. Concrete matrix compositions shown in Table 1, the fiber content was taken from 1 to $2.0 \%$ by volume.

Figures 5 and 6 shows the results of tests by determining the compressive strength and tensile strength at bending of samples of different compositions of concrete at the age of 28 days with a glass-plastic fiber content from 0.5 to $2.0 \%$ by volume.

According to the test results found that the tensile strength at bending of concrete classes B20, B30 and B40 with glass-plastic fibers from 0.5 to $2.0 \%$ by volume is increased up to 36,21 and $14 \%$ respectively. The compressive strength of concrete classes $\mathrm{B} 20, \mathrm{~B} 30$ and $\mathrm{B} 40$ is also increased up to 10,9 and $7 \%$ respectively. Thus, increasing the concrete class reduces effect from introducing fibers. Tensile strength at bending of concrete class B40 with glass-plastic fiber at different ages almost did not change in 
percentage to the control composition without fiber (Figure 7), what shows sufficient adhesion of fibers and concrete matrix with the joint efficient action during the curing of fiber concrete.

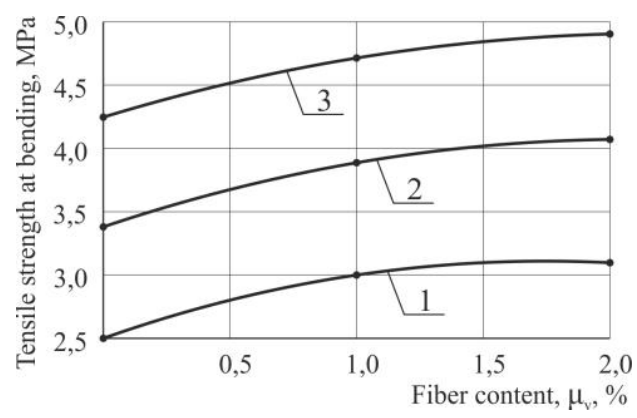

Fig. 5. Tensile strength at bending, 1, 2 and 3- concrete class B20, B30 and B40 respectively.

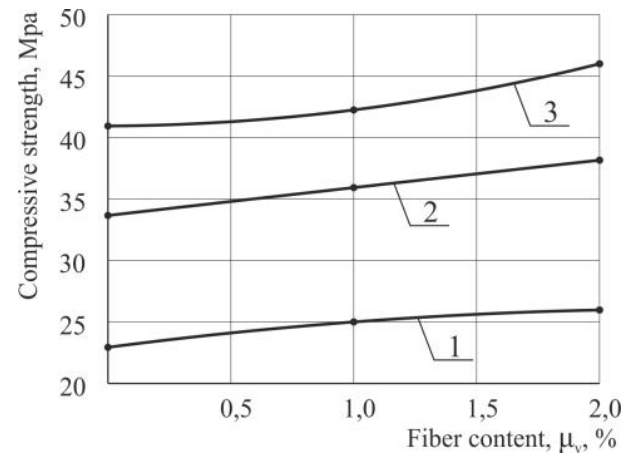

Fig. 6. Compressive strength, 1, 2 and 3- concrete class B20, B30 and B40 respectively.

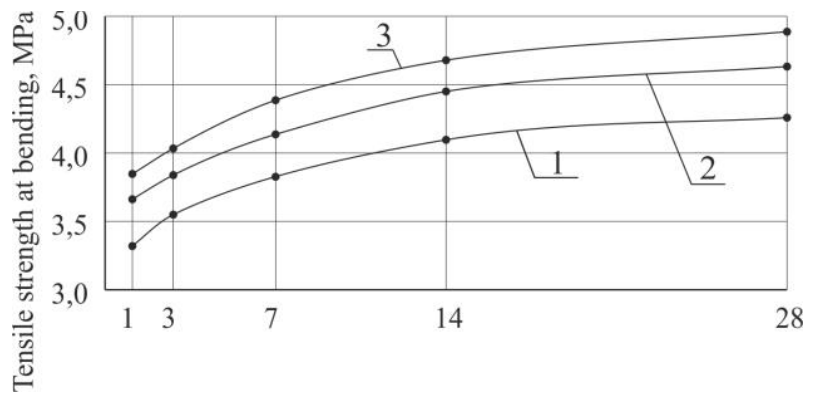

Fig. 7. Tensile strength at bending change by days. 1- concrete without fiber, 2- $1 \%$ fiber content, 3$2 \%$ fiber content.
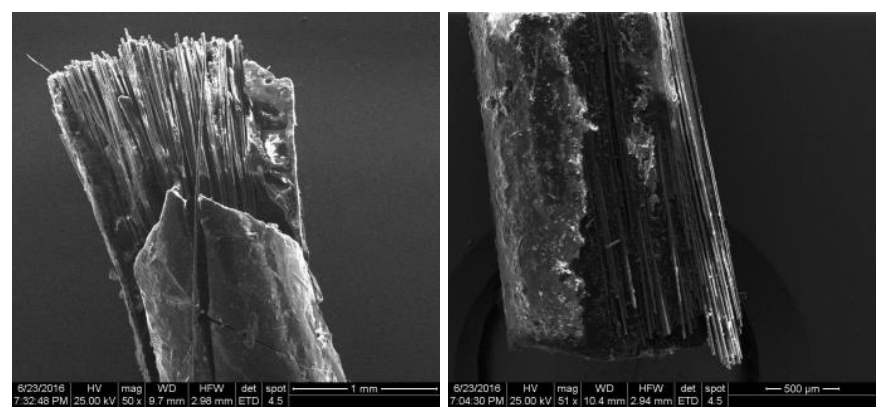

Fig. 8.9 Shell of glass-plastic fiber after the tensile strength test at bending. 
The shell of glass-plastic fiber after the tensile strength test at bending in the specimens deformed and partially destroyed - Figure 8, 9. Lower strength of glass-plastic fiber shell does not allow achieving results comparable with steel analogs, because shell destruction leads to slipping out fiber in concrete matrix. Thus, absence of breaks in individual fibers indicates the possibility of improving its efficiency in the concrete matrix. Better results may be obtained by using of glass-plastic fibers with a geometric factor $80 \ldots 100$ [5], either a directed change in the structure and properties of the concrete matrix [6,7], which is due to increasing efficiency of fixing of fiber in the matrix and the properties of the resulting fiber-reinforced concrete in total .

\section{Conclusions}

These results display that the investigated glass-plastic fibers work in different concrete matrices as a high modulus reinforcing disperse component, and improves the strength properties of fiber reinforced concrete. However, at the present time is necessary to make extra complex studies aimed at improving the efficiency of glass-plastic fibers in concrete, for its wider use as steel fiber analog. Some differences of glass-plastic fiber from the steel fiber - low density and thermal conductivity, absence of balling effect while mixing concrete and corrosion resistance to different environments, all this define huge opportunities for its effective use in the manufacture of fiber reinforced concrete products and structures.

\section{References}

1. V.G. Solovyev, A.F. Buryanov, M.S. Yelsufyeva, Stroitel'nye Materialy 3, 18-21 (2014)

2. M. Rangelov, S. Nassiri, L. Haselbach, K. Englund, Construction and Building Materials 126, 875-885 (2016)

3. A. El-Nemr, E.A. Ahmed, C. Barris, B. Benmokrane, Construction and Building Materials 113, 77-89 (2016)

4. E.A. Khoteyev, Transport Construction 1, 10-13 (2015)

5. F.N. Rabinovich, The composites on the basis of dispersed-reinforced concretes (Izdatel'stvo ASV, Moscow, 2011)

6. M.S. Elsuf'eva, V.G. Solovyev, A.F. Bur'yanov, Stroitel'nye materialy 8, 60-63 (2014)

7. V.G. Solovyev, A.F. Bur'yanov, H.-B. Fisher, Stroitel'nye materialy 9, 43-46 (2015) 